Fournal of Medical Genetics (1972). 9, 264.

\title{
The Use of New Staining Techniques for Human Chromosome Identification
}

\author{
PETER PEARSON \\ Department of Human Genetics, Leiden University, The Netherlands
}

An accepted feature of technological development and its associated accumulation of data is that progress occurs in an irregular fashion with 'break throughs' being interspersed by periods of relative inactivity. In the halcyon years of 1955 to 1961 , human cytogenetics experienced a revolution which brought the field within the scope of most genetic laboratories. The resulting increase in the volume of cytogenetical data being published has seen few parallels in the history of science. A review of the period (Hamerton, 1962) amply demonstrates the accurate level of information gathered over this era, and one concludes that, with the exception of autoradiographic information at that time, the technique not yet having been applied to human cytogenetics, very little new information was collected over the next 8 years. The majority of contributions merely emphasized biological situations known to exist and described in part previously. Over this period, the limitations in identifying human chromosomes on morphological criteria remained a major deficiency of the work and the IIIrd Chromosome Standardization Conference (Chicago Conference, 1966) summarized and defined those chromosomes which could be further specified by a combination of their morphological and autoradiographic patterns. Only those who have had cause to use autoradiography for chromosome identification will appreciate the strictures imposed by time, resolution, and sample size by this technique.

This was the less than satisfactory state of the art in late 1968 when a group from the Karolinska Institute, Stockholm, led by T. Caspersson, published what was to be the first of an astonishing series of papers. In the first paper (Caspersson et al,

Received 2 March 1972.
1968) they described observations on the appearance of Chinese hamster and bean chromosomes stained with a fluorescent dye-quinacrine mustard-and viewed under an appropriately adjusted, ultraviolet illuminated microscope. From the clear pictures provided in the article, it was apparent that the chromosomes had varying quantities of the fluorochrome bound along their length. The authors stated that the distribution of fluorescence along the chromosomes was constant for each pair of chromosomes, and that this reflected difference in the chemical composition of different portions of the chromosomes. Since the fluorochrome used contained a terminal mustard configuration in the molecular sidechain, and since alkylating groups of the mustard variety have a well-known affinity for the N-7 atom of guanine (Brookes, 1964) the authors concluded that they were staining up differences in the base composition of the DNA. As subsequent events showed, and will be outlined below, this view has had to be modified, but for an initial hypothesis it was extremely stimulating because it pointed towards the possibility of examining the DNA composition of individual chromosomes and perhaps using this for their identification.

At the time, mainly through difficulties in obtaining quinacrine mustard, few laboratories followed up the leads provided by this first paper, and it was not until November 1969 when the Karolinska group produced further papers in the series in quick succession (Caspersson et al, 1969a, 1969b, and 1970d; Zech, 1969) did most laboratories take a further interest in the matter. In one of these, Lore Zech briefly mentioned that when human chromosomes were stained with quinacrine mustard, then the $\mathrm{Y}$ could always be easily recognized by virtue of the distal ends of its long arms being much more intensely fluorescent than any other 
chromosome region. This was quickly verified in Oxford, using the much more easily obtainable antimalarial drug, quinacrine dihydrochloride*, and they also showed that interphase cells (Pearson, Bobrow, and Vosa, 1970) could be sexed dependent upon whether or not they contained a small, brightly fluorescent body in their nuclei. By comparing the cells from $\mathrm{XX}, \mathrm{XY}$, and $\mathrm{XYY}$ individuals, it was shown that the fluorescent body represented the

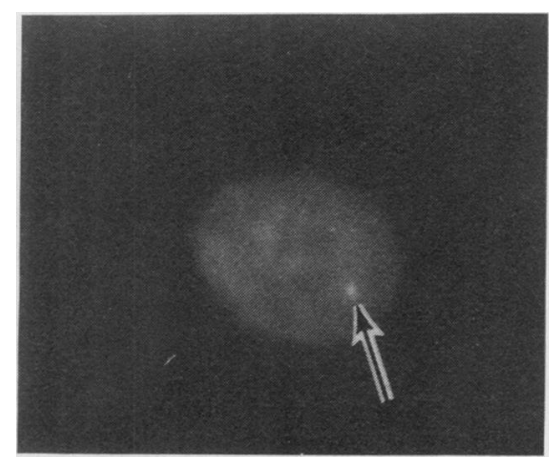

Fig. 1a. Oral mucosa cell from $\mathrm{XY}$ male with a single $\mathrm{Y}$ body.

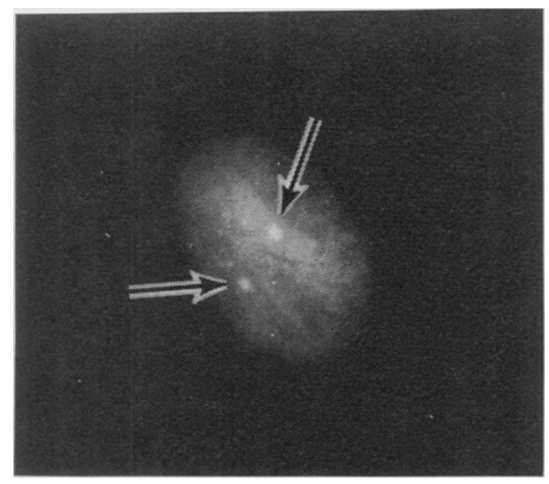

FIG. 1b. Oral mucosa cell from XYY male with 2 widely separated $\mathrm{Y}$ bodies.

interphase state of the fluorescent end of the $\mathrm{Y}$ chromosome. While in general female nuclei contained no bodies, normal male nuclei appeared to contain a single one (Fig. 1a) and those from XYY individuals, or fibroblasts from $\mathrm{XY}$ males which had become polyploid in culture, an average of 2 fluorescent bodies (Fig. 1b). The term given to the fluorescent bodies was the Y body (Pearson, 1970) to distinguish it from the long recognized Barr body. It has more recently been demonstrated

\footnotetext{
* Trade name-Atebrin.
}

(François et al, 1971; Schwinger et al, 1971; Mukherjee, Blattner, and Nitowsky, 1972) that both $\mathrm{Y}$ and Barr bodies can be seen after quinacrine staining in hair follicle and tissue culture cells. It is likely that this is caused by higher concentrations of chromatin rather than chemical similarities between $\mathrm{Y}$ and Barr bodies.

Practical uses for the sexing of interphase cells have been the calculation of rates of $Y$ chromosome non-disjunction in the formation of male gametes (Pearson and Bobrow, 1970a; Sumner, Robinson, and Evans, 1971b) (see Figs. 2a, and 2b), the detection of XYY individuals in a new-born population (Robinson, 1971) and categorizing the sex

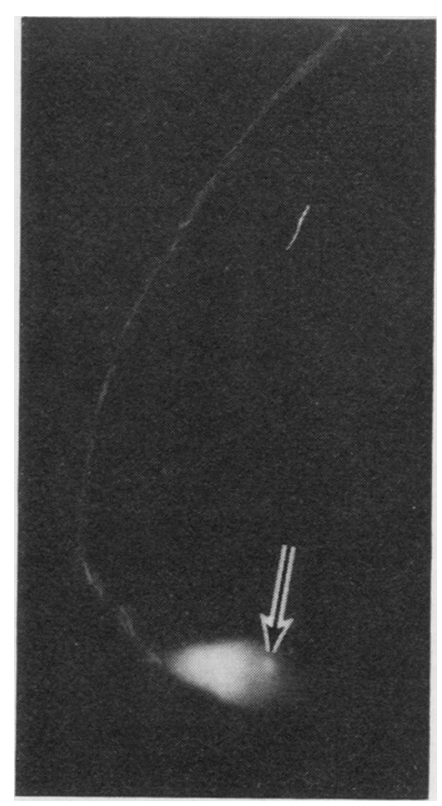

Fig. 2a. Haploid sperm with a single $Y$ body.

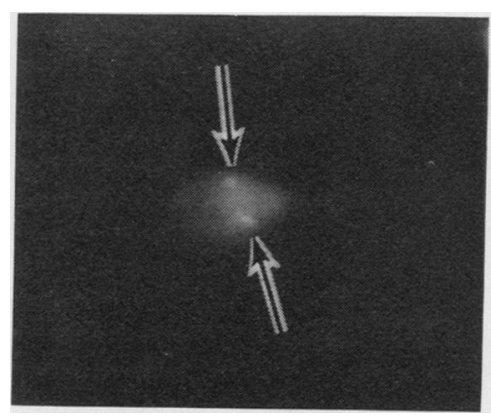

FIG. 2b. Haploid sperm with $2 \mathrm{Y}$ bodies-this presumably contains $2 \mathrm{Y}$ chromosomes and is found in $2 \%$ of normal spermatozoa. 
chromosome status of various intersex states (Polani and Mutton, 1971). In the cold light of clinical diagnosis, the technique appears to be extremely robust, particularly when used in combination with the Barr body test, which can be carried out on the same batch of cells after prior examination with the fluorescence technique. However, unlike the Barr body test, practically any type of interphase cell can be used for $\mathrm{Y}$ body analysis. Since there are now 2 types of sex chromatin, the proposal was made and adopted at the recent Standardization Conference held at Paris (Orly) in 1971 that the term sex chromatin be no longer used, and the more specific nomenclature of $\mathrm{X}$ chromatin and $\mathrm{Y}$ chromatin be used instead to refer to the Barr and $\mathrm{Y}$ bodies respectively.

The ease with which the $\mathrm{Y}$ chromosome can now be recognized has merited examination of the wellknown length polymorphism of the human $Y$ chromosome (Cohen, Shaw, and MacCluer, 1966, amongst others). To date, 2 publications (Bobrow, et al, 1971b; Schnedl, 1971a) are available on this topic, both showing that practically all the length variation is present in the intensely fluorescent portion of the $\mathrm{Y}$ chromosome with increases and decreases in the length of the chromosome directly reflecting similar changes in the fluorescent portion. It was not very surprising, therefore, when normal males were described possessing very short $\mathrm{Y}$ chromosomes which lacked an intensely fluorescent portion (Borgaonkar and Hollander, 1971). It was pointed out by the authors that the interphase cells of such individuals would be incorrectly sexed by the $\mathrm{Y}$ body test. However, individuals with very small $\mathrm{Y}$ chromosomes are quite rare $(<0 \cdot 1 \%$ in the Oxford area) and misidentification of the nuclear sex for this reason will be infrequent. Structural rearrangements of the $\mathrm{Y}$ chromosome, including dicentrics, have been carried out (Bühler et al, 1971; Robinson and Buckton, 1971, amongst others) and it is now apparent that in at least one case, a chromosome which had been supposed to have been a $\mathrm{Y}$ on morphological criteria had, in fact, been derived from an X chromosome (Stevenson, Bedford, and Barberton, 1971). The lack of intensely fluorescent $\mathrm{Y}$ chromatin has been demonstrated in XX males by several groups (George and Polani, 1970; Caspersson et al, 1971b, amongst others) whilst testing Ferguson-Smith's hypothesis (1966) that the male phenotype is caused by translocation of $\mathrm{Y}$ chromatin onto another chromosome. However, these results do not disprove the hypothesis but state that the intensely fluorescent portion of the $Y$ chromosome is absent and say nothing about the presence of non-fluorescent $\mathrm{Y}$ chromatin. Fialkow and his coworkers (1971) have traced male cells in the marrow of a leukaemic girl who several months previously had received a marrow transplant from her male sib. In this elegant use of the fluorescent technique, the group demonstrated that the donor cells had also experienced leukaemic transformation.

Intensely fluorescent chromatin is also variably found in specific locations on several of the autosomes, namely the centromere region of chromosomes Nos. 3, 4, and the short arms and/or the satellites of all the acrocentric chromosomes. The position and frequency of these polymorphisms seems to be constant for individual chromosomes. For example, the presence of intensely fluorescent short arms on a long acrocentric chromosome is characteristic of chromosome 13 and large, intensely fluorescent satellites on a short acrocentric chromosome of chromosome 22. There appears to be a continuous size variation in these autosomal polymorphisms, and because of this, different laboratories and observers will establish different criteria for describing the polymorphisms. This is a procedural difficulty which has still to be resolved if realistic comparisons are to be made between the frequencies from different laboratories.

The functional purpose of the intensely fluorescent chromatin at present remains obscure. How- 8 ever, there are 2 interesting observations which are relevant to this matter.

(1) In the mammalian kingdom, the presence of: intensely fluorescent chromatin is confined to man, chimpanzee, and the gorilla (Pearson et al, 1971): this implies that the chromatin is fairly recent in origin and has not been an essential component in the evolution of mammalian karyotypes. Indeed, since it is variably present in man, there is reason for the belief that it serves a non-essential function, at least to the extent with which individuals appear to have a normal metabolism in its absence.

(2) The fluorescent chromatin is physically associated with the nucleolus (Gagné and Laberge, 1971; Bobrow, Pearson, and Collacott, 1971a) and may therefore also be functionally associated. If so, it could be used for transcribing nucleolar RNA, a function which is thought to be also borne by the secondary constriction regions. In addition, it consists of repetitive nucleotide sequences of DNA which is similar to known RNA transcribing regions of chromosomes in other organisms-see for example Ritossa et al (1966) and may thus act as a form of gene amplification recognized in amphibians (Gall, 1969) and insects (da Cunha et al, 1969).

Although the areas of intensely fluorescent chromatin appear to vary from one individual to another, other parts of the chromosomes have a consistent 


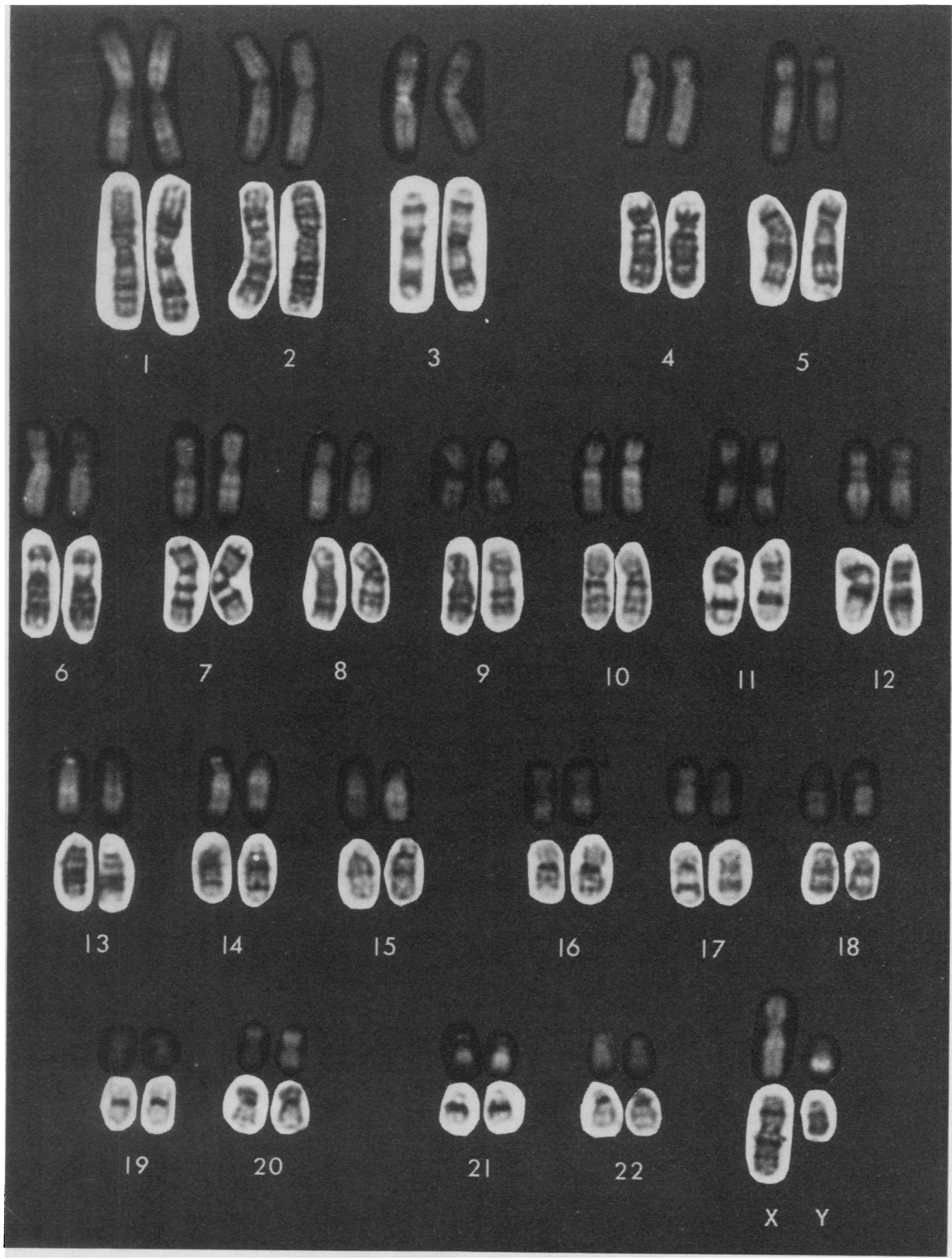

Fig. 3. A fluorescent karyotype has been set out on the black background. A Giemsa-stained karyotype has been set out below each line on a white background for comparison with the fluorescent karyotype. 
pattern of fluorescence, typical for each pair of chromosomes. This pattern, described by Caspersson, Lomakka, and Zech (1971e) has now been adopted by the IVth Chromosome Standardization Conference (Paris Conference, 1972) as the basic banding pattern used for distinguishing each and every chromosome. The variation in intensity of fluorescence used for this is very low, and the process of analysis is aided by some form of contrast enhancement usually produced photographically. From a suitably processed bromide print of a set of chromosomes, a karyotype can be derived (Fig. 3). In this way, identification has been made of the chromosome present in a trisomic state, and hence it has been recognized as chromosome 21 in cases of Down's syndrome (Caspersson et al, 1970b, amongst others) and also that the Philadelphia chromosome is produced from chromosome 22 in patients suffering from myeloid leukaemia (Caspersson et al, 1970a; O'Riordan et al, 1971). In addition, a rapid confirmation of the identity and fluorescent pattern of chromosomes involved in centric fusion translocations (Breg et al, 1971; D. A. Miller et al, 1971a), X chromosome (Caspersson, Lindsten, and Zech, 1970c), and B group (Bobrow and Pearson, 1971) anomalies has been made. However, the human eye-brain combination is an excellent device for pattern recognition, and with practice visual analyses can also be carried out directly down the fluorescent microscope. Under these circumstances, there is a time factor involved, since the quinacrine dye fades rapid with illumination. Thus, an effective examination of any one cell should occupy less than 3 to 4 minutes, and a photograph is the only means of maintaining a permanent record of the fluorescent pattern. Quantitative comparisons of the position and relative intensity of different bands can be carried out using microdensitometry on photographs of the chromosomes (Caspersson et al, 1971a and d) and is useful not only for recognizing the chromosomes involved but also the position of the breakpoints in structural rearrangements (Bobrow and Pearson, 1971).

It seems, therefore, that at long last a technique is now available for identifying all the human chromosomes, albeit with certain restrictions for those centres who have neither the necessary experience nor the equipment to use the fluorescent system to the best of its advantages.

The next part of the story developed at an opportune time for those laboratories who were either financially unable to or were still contemplating updating their microscope equipment for fluorescent analysis. The initial observations were made by
Pardue and Gall (1970) who, whilst developing techniques for hybridizing RNA onto mouse chromosome preparations, noted that an area adjacent to the centromere region of each chromosome stained much more deeply with Giemsa than the rest of the chromosome. The preparations could be examined with a standard bright field microscope, and did not require expensive fluorescence equipment. Under the conditions of the experiment, which involved denaturing the chromosomal DNA followed by renaturation, ie, separating the double stranded DNA into its constituent strands and then back again, the areas which were darkly stained were found to be those areas which renatured more rapidly than any other. Theory (Britten and Kohne, 1968) would predict that the DNA in these regions consists of more highly repetitive sequences than those present elsewhere. Arrighi and Hsu (1971) modified the technique slightly and extended the observations to the chromosomes of different mammals, including man. They demonstrated that, after treatment, all human chromosomes had deeply staining areas next to their centromeres (Fig. 4), and that particular chromosomes had larger areas than did others. In general, the larger areas corresponded to the secondary constriction regions of chromosomes 1, 9, and 16, and those parts of Nos. 3,4 , the acrocentrics, and $Y$ which exhibit intensed fluorescence with the quinacrine technique. Although these areas consist of repetitive DNA sequences, they do not appear to be all identical in base composition. By DNA hybridization, Saunders et al (1972) have demonstrated that the band on chromosome 9 consists of a particular fraction of repetitive DNA which differs from any of the other highly repetitive centromere regions in base composition. Jones and Corneo (1971) have also isolated out a fraction of DNA which seems to be homologous with the centromere regions of chromosomes 1,16 , and perhaps 9 . This, therefore, is a different DNA fraction to that isolated by Saunders et al (1972), and clearly demonstrates that secondary constriction regions differ in the composition of their DNAs. This chemical heterogeneity has been corroborated (Bobrow, Madan, and Pearson, 1972) by a simple Giemsa staining variation which principally stains the secondary constriction region of chromosome 9, and leaves the majority of centromere regions unstained (Fig. 5). In addition, it will reveal the presence of the No. 9 chromosome in interphase nuclei, including spermatoza (Fig. 6).

Occasionally, when human chromosomes are treated and stained for centromeres, they exhibit banding patterns along their length similar in size and position to those produced by quinacrine 


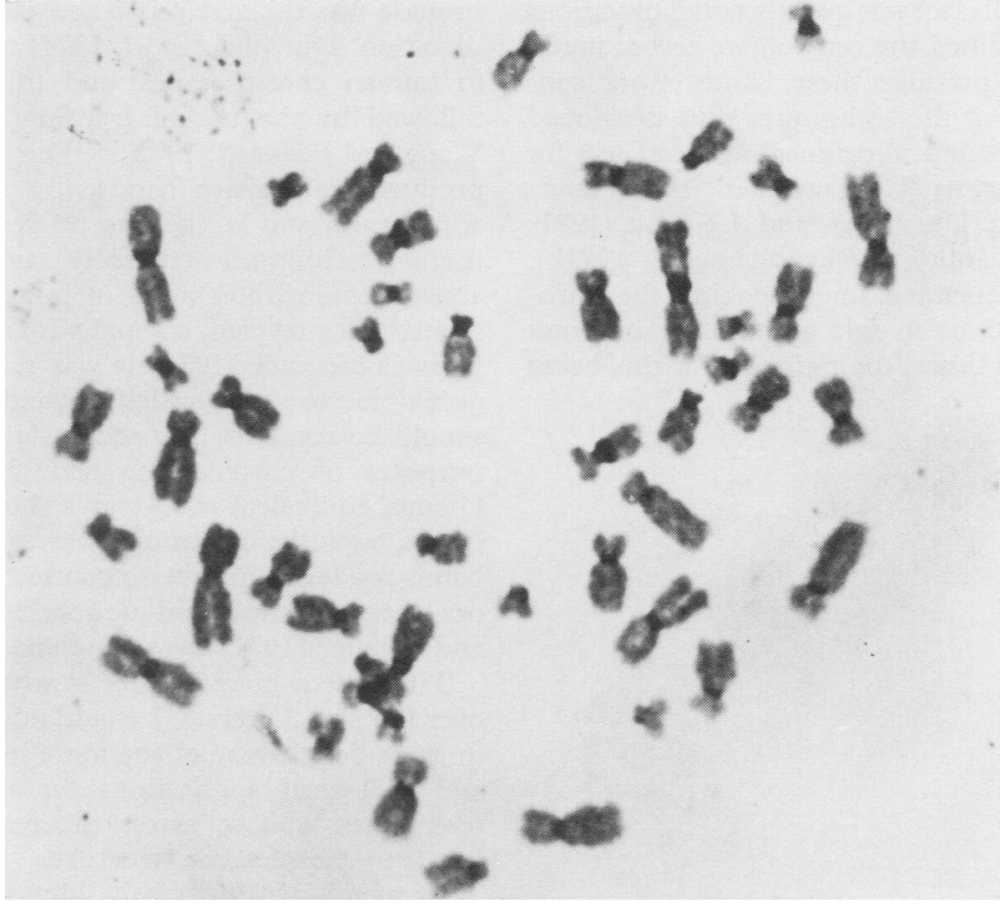

Fig. 4. Centromeric bands (after Arrighi and Hsu [1971]).

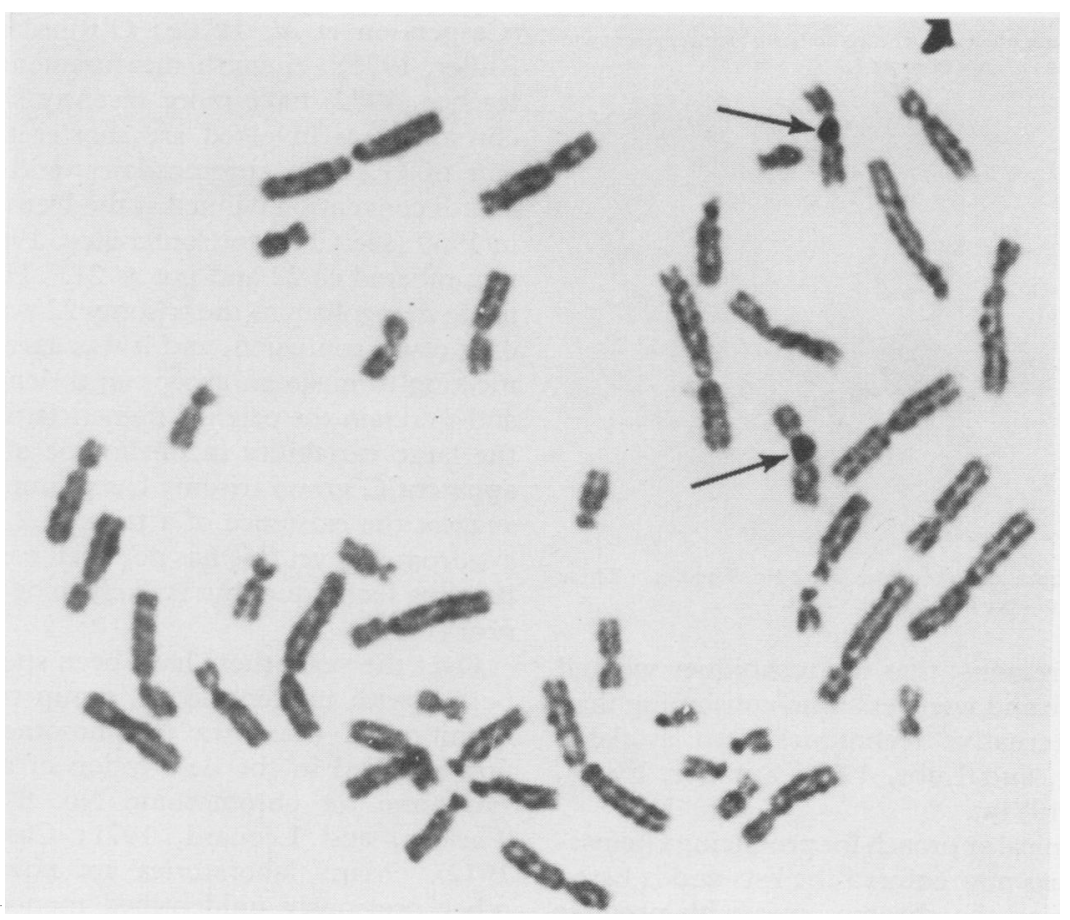

FIG. 5. Preferential staining of the secondary constriction regions of chromosome 9. 
flourescence. This fact was quickly noted by various workers who modified the centromere technique in various ways to produce these bands more consistently. Some of the techniques thus developed retained denaturation and reannealing sequences for various time intervals (Chernay et al, 1971; Drets and Shaw, 1971; Dutrillaux and Lejeune, 1971; Lomholt and Mohr, 1971; Schnedl, 1971b). Others simply depended upon soaking the chromosome preparations in salt solutions at different temperatures and times, the rationale for this being

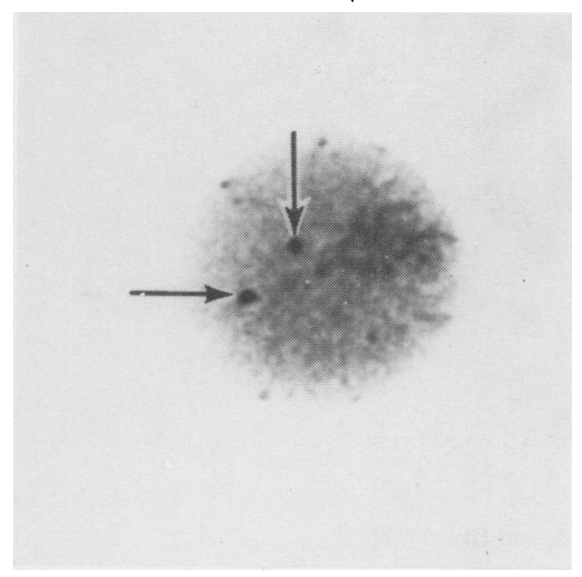

FIG. 6a. An interphase nucleus with two bodies which represent the secondary constrictions of chromosome 9 .

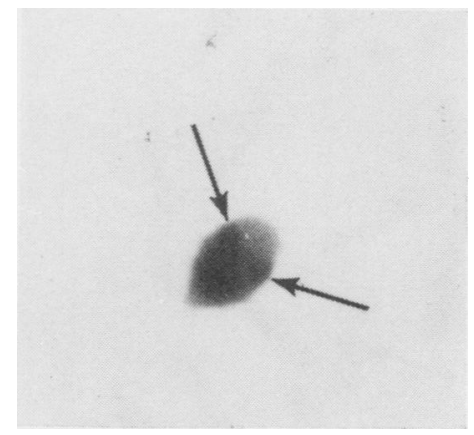

Fig. 6b. Spermatozoan nucleus containing 2 No. 9 bodies. These occur at a frequency of over $1 \%$ in fertile males.

the best of all reasons, that the techniques worked most of the time and were less time-consuming than any of the alternative techniques then available (Patil, Merrick, and Lubs, 1971; Sumner, Evans, and Buckland, 1971a).

Another technical approach for producing Giemsastained bands has now entered the lists and is based on briefly treating the chromosomes with protease solutions followed by Giemsa staining. The use of pronase was the first published example of enzyme digestion (Dutrillaux et al, 1971) to produce bands in human chromosomes, and this has now been followed by the use of trypsin (Seabright, 1971; Wang and Fedoroff, 1972). The trypsin treatment produces dark sharp bands of a most spectacular appearance, and is likely to prove one of the most useful techniques currently available. Fig. 3 above demonstrates a set of human chromosomes treated with trypsin, stained with Giemsa. At the Paris Conference (1972) it was recommended that quinacrine bands be called Q-bands, and that these should be recognized as the basic band pattern for purposes of chromosome identification, that the Giemsa equivalent of Q-bands should be called Gbands, and the centromere areas C-bands. The bands produced in reverse contrast to either the Qor G-bands by the technique developed by Dutrillaux and Lejeune (1971) were designated as R-bands.

This, then, gives a brief synopsis of the events over the past 2 years. I would now like to describe in more detail some of the more interesting clinical and biological applications for the identification techniques, and to assess the relationship of the bands to chromosome structure.

As mentioned previously, identification has been made of the $G$ group chromosome present as a trisomic in patients with Down's syndrome (Caspersson et al, 1970b; O'Riordan et al, 1971; Ridler, 1971). Length measurements (Paris Conference, 1972) have more recently shown that the chromosomes involved are shorter than the other pair of $G$ group chromosomes, and hence by the length convention defined at the Denver Conference in 1960 (see Chicago Conference, 1966), should be renumbered as 22 and not as 21 . However, to rename mongolism as the trisomy 22 syndrome would only cause confusion, and it was agreed at the Paris meeting to make an exception to length ordination and to retain the original nomenclature. Although the large variability in phenotype of patients with apparent $\mathrm{G}$ group trisomy has prompted workers to suggest the existence of a trisomy 22 as well as 21 syndrome, as yet this has not been confirmed by the banding techniques but is likely to be resolved in the near future.

Over the years there have been sporadic cases reported with unidentified $\mathrm{C}$ group trisomies. Recognition of the extra chromosome involved has now resulted in the description of a new trisomic syndrome for chromosome No. 8 (de Grouchy, Turleau, and Léonard, 1971; Caspersson et al, 1972). Many laboratories are now re-evaluating other previously unidentified monosomic and trisomic conditions (see, for example, Caspersson et al, 
1971c; Malpuech et al, 1971; numerous contributions in the abstracts of the Fourth International Congress on Human Genetics, 1971), and in combination with the analysis of unbalanced progeny from translocation heterozygotes this will permit phenotype-karyotype correlations to be gradually built up for all the chromosomes. This is a long term process and as yet it is too early to draw any conclusions but at least one can expect an early confirmation and perhaps redescription of the $4 p-$, $13 q-, 18 p-, 18 q-, 21 q-$, and $22 q-$ deletion syndromes described previously on the basis of morphological and autoradiographic information.

One of the most surprising features in the case of banding patterns has been the accuracy with which most of the breakpoints in structural rearrangements can be identified. In many instances the breakpoint can be defined to an accuracy within 0.5 microns and the distribution of breakpoints, relative to the position of bands, assessed. It is apparent from analysis of over 50 structural rearrangements at the Population Genetics Unit, Oxford (unpublished data) that a disproportionately large number of breaks occur in either the centromere or telomere regions. It has been suggested (in the discussion to Buckton et al, 1971) that such a distribution reflects a bias in identifying rearrangements which show a maximal change in the shape of the chromosomes. However, fluorescent studies carried out on lymphocyte chromosomes damaged by irradiation in vitro and in vivo (C. J. San Roman, personal communication) show clearly a non-random distribution of breaks caused by the significant involvement of the centromere and telomere regions.

Using morphological criteria, structural rearrangements can be detected only if they result in a change in shape of the chromosomes. Because of this, equal exchanges must go unnoticed. Although meiotic analysis can compensate for the lack of information (McIllree et al, 1966) the banding techniques are a much simpler and extremely powerful tool for detecting hidden rearrangements (Evans, Buckton, and Sumner, 1971). Banding analysis of chromosomes in tumour cells (Manolov et al, 1971), lymphoblast cells (Steel, 1971), and long established in-vitro heteroploid cell lines of both murine and human origin (O.J. Miller et al, 1971b; Allderdice et al, 1972) have revealed a wealth of karyotypic change which went unnoticed beforehand. Of particular interest have been the results of $O$. J. Miller et al (1971b) on Hela cell chromosomes, from which they conclude that most of the karyotypic changes found are explicable in terms of increases and decreases in the number of apparently normal chromosomes and that structurally rearranged chro- mosomes represent only a small proportion of the variation present.

Gene linkage studies based on somatic cell hybrids between human/mouse or human/hamster combinations depend upon the preferential loss of most of the human chromosomes from the cells and the subsequent identification of which human chromosomes and enzymes remain. One of the major difficulties with this has been to identify accurately which human chromosomes are retained against the chromosome background of a continuously varying heteroploid cell line. To date, published contributions have based their identification on differences in centromere band size (Chen and Ruddle, 1971; Rowley and Bodmer, 1971) and fluorescent patterns (Caspersson et al, 1971f; O. J. Miller, Allerdice, and D. A. Miller, 1971a). In the latter study, the retention of human thymidine kinase activity along with chromosome 17 was confirmed. More recently an elegant study (Grzeschik et al, 1972) has been carried out in which the human $\mathrm{X}$ chromosome was reciprocally translocated onto an autosome, that is, it was divided into 2 parts, so that each part could be identified in a hamster host cell by th: fluorescence technique. HGPRT and G6PD activity was lost with the short arm of the $\mathrm{X}$ chromosome and PGK activity with the long arm portion. This study is now being repeated using other $\mathrm{X}$ autosome translocations, and comparison of enzyme and chromosome segregation patterns should permit an overlapping map for the position of genes on the $\mathrm{X}$ chromosome to be built up.

Meiotic chromosomes have also received attention, and it has been shown by fluorescence that the short arms of the $\mathrm{Y}$ chromosome pair with the $\mathrm{X}$ (Pearson and Bobrow, 1970b), and that, contrary to most previous evidence, a proportion of XYY males transmit their extra $\mathrm{Y}$ chromosome to their gametes. In doing so, because of the pairing behaviour of the $2 \mathrm{Y}$ chromosomes at metaphase 1, they form few YY gametes (Hultén and Pearson, 1971). Indeed, one would predict that given normal disjunction such individuals will produce only $X$ and $X Y$ gametes and are much more likely to father Klinefelters than they are XYY individuals. Although the bands seem to be extremely indistinct, fluorescent analysis has also been used to identify autosomal bivalents (Caspersson et al, 1971f) and to map the position and frequency of chiasmata (see meiotic report in Paris Conference, 1972). Combined with the C-banding technique which can be used for revealing the location of centromeres (see Fig. 7) it seems that bivalents can be identified in most cells but that variation in the quality of staining prevents a complete characterization of every cell. 


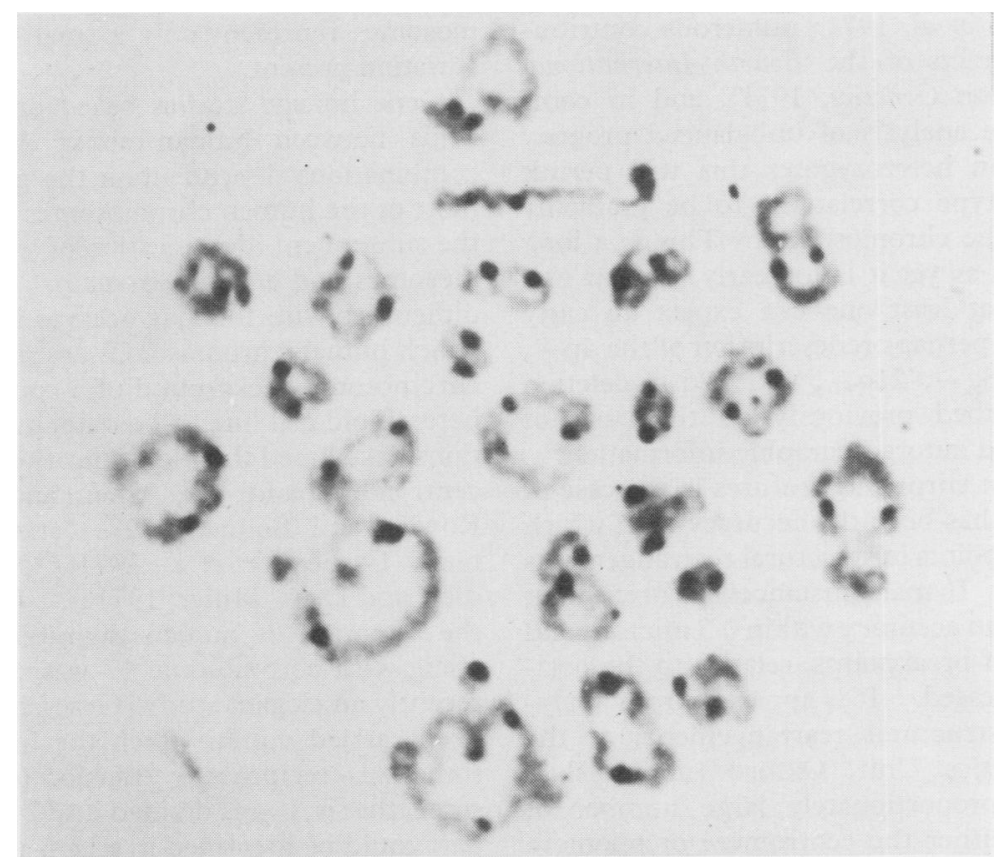

FIG. 7. Centromere bands in human meiotic chromosomes.

Human chromosomes have not been the only target for the banding techniques. Studies are currently in progress on the banding patterns in chromosomes of the cow (Hansen, 1971); sheep, goat, and mouse (Franke and Nesbitt, 1971; Schnedl, 1971c; Dev et al, 1971) amongst mammals of high scientific and economic value. Murine studies are progressing extremely quickly, and by using translocation marker stocks, linkage groups are being assigned to individual chromosomes (D. A. Miller et al, 1971b; O. J. Miller et al, 1971c).

Other areas of work include comparative chromosome studies for assessing phylogenetical relationships. Pearson, Bobrow, and Madan (1972) have compared the banding patterns of the hominoid apes and found a remarkable similarity of the bands in man to those found in the chimpanzee and gorilla, with relatively few similarities existing between those species and the orang-utan. The study has also verified Ohno's prediction (1969) that the X chromosome is conservative and evolves much more slowly than any other chromosome in that, unlike the autosomes, the $\mathrm{X}$ chromosome banding patterns were found to be identical for all hominoid apes studied. This implies that the hominoid $\mathrm{X}$ has remained unchanged for perhaps the last 30 to 50 million years. With the exception of the $\mathrm{X}$, no similarities in bands could be found between man and the gibbon. It can be argued that, although genetical homology exists, it is at too fine a level to be detected by the banding techniques. Similarly, recognition of small pieces of chromatin in translo-60 cation and hybrid cell material must depend upon? their retaining sufficient band information. This must impose a lower limit to the resolution of the system which will vary with the chromosome and banding technique under consideration. On average for the quinacrine fluorescence, empirical observation (Pearson et al, 1972) sets the limit to half of one arm from one of the larger chromosomes or to a length of between 2 and 3 microns.

Significance of the Bands. Perhaps one of the most astonishing features has been the similarity in banding patterns produced by the different techniques. Exceptions to this are the centromeric bands or highly iterative regions of DNA, which stain differently with different techniques. However, for the other areas, the similarities must reflect a common underlying organization of the chromosome at the physicochemical level. What evidence is there for such an organization? I have drawn together the following conclusions which explain some, but not all, of the observed phenomena.

(1) Quinacrine presumably binds to DNA by intercalation of the tricyclic acridine nucleus into the DNA helix (Kurnick and Radcliffe, 1962). How- 
ever, its long molecular sidechain is important for differential binding such that if the chain is absent or suffers minor changes in molecular structure (P. L. Pearson, unpublished data) the differential staining effect is lost. Competition studies with methyl green, which is believed to attach to the outside of the helix, suggest that dislodging the sidechain also displaces the whole molecule. This implies that quinacrine binding is a 2-phase process (Kasten, 1966) with both intercalation of the nucleus to DNA and binding of the sidechain to extra helical sites.

(2) The major dye components of Giemsa appear to be methylene blue, eosin, and azure $\mathrm{A}$ and $\mathrm{B}$. Methylene blue and the azures have tricyclic structures remarkably similar in size to the quinacrine nucleus. It has been demonstrated by A. Sumner (personal communication) that after staining chromosomes treated in a time series with a hot salt solution, the chromosomes first stain blue without any visible banding, and later start to turn red, at which point bands appear. He suggests that the staining is a 2-phase process with uptake of the methylene blue followed by differential binding of a red dye component, probably eosin, to form a molecular hybrid with the methylene blue. Note the resemblance in behaviour between the nucleus and sidechain of quinacrine on the one hand with methylene blue and red dye component on the other.

(3) Following an elegant series of experiments on the chromosomes of the Indian Muntjac, Comings (1971) has proposed that banding patterns do not reflect differences in the distribution of base composition (Caspersson et al, 1970d) highly repetitive sequences of DNA or histone distribution and, in the absence of any other causative agent, proposes that the distribution of acidic proteins may be responsible for differential dye binding. This would be compatible with the idea that binding of the quinacrine sidechain and red dye component in Giemsa is determined by a protein moiety attached to the DNA helix.

(4) Further support for a protein distribution causing differential dye binding is provided by the protease digestion procedures for producing bands. The dilute enzyme solutions presumably 'strip' off surface proteins and this may occur in a differential fashion.

(5) The way in which the techniques have evolved has given rise to the theory that the Giemsa procedures are dependent upon denaturation of some chromosome areas and not others. Acridine orange studies by $\mathrm{D}$. Mutton (personal communication) have verified that when chromosomes are treated with hot salt solutions they appear to be stained metachromatically. Acridine orange staining is notoriously difficult to interpret (Kasten, 1966) but one explanation would be that the areas corresponding to quinacrine and Giemsa bands are single stranded and interband areas double stranded. Untreated chromosomes seem to be double stranded so that the treatment with the salt solution proceeds in the direction of denaturation and not reannealing.

(6) From the above points, we can perhaps infer that staining is primarily dependent upon an acidic protein distribution, and that this reflects the relative ease with which different regions can be denatured. The rate of denaturation may reflect variations in the repetitious nature of the DNA (Britten and Kohne, 1968) or it may depend upon the differential removal of binding proteins which maintain DNA in its native state (Clark and Felsenfeld, 1971). Further than this we cannot say at the present time.

\section{Conclusion}

The past 2 years have been an exciting time for all concerned. The practical superiority of the new techniques is so great that morphological identification can no longer be regarded as adequate. Laboratories now have to decide not whether they are going to use the banding techniques but which one will be the most suitable for their purposes. The fluorescent technique is largely dependent upon having adequate equipment, and whilst expense will place it beyond the reach of some laboratories, it does have certain advantages over other techniques which merit attention. It is a technique which can be used for sexing cells and in which both intensely fluorescent areas and chromosome bands can be seen on the same chromosome preparation. In addition, the technique does not appear to suffer from the vagaries of day to day variation in quality as do the others. However, assuming that the Giemsa banding techniques will be modified to achieve a higher level of reliability, they have obvious advantages over the quinacrine fluorescence. They require ordinary bright field microscopes, and the preparations are permanent. Although these considerations are likely to make the Giemsa techniques firm favourites with diagnostic laboratories, research workers will use combinations of all techniques as the occasion arises.

\section{REFERENCES}

Allderdice, P. W., Miller, O. J., Pearson, P. L., Klein, G., and Harris, H. (1972). Chromosome analysis of two related heteroploid mouse cell lines by quinacrine fluorescence. (In preparation.)

$\checkmark$ Arrighi, F. E. and Hsu, T. C. (1971). Localization of heterochromatin in human chromosomes. Cytogenetics, 10, 81-86.

Bobrow, M., Madan, K., and Pearson, P. L. (1972). Variation in the staining of centromeres of different human chromosomes. Nature. (In press.) 
Bobrow, M. and Pearson, P. L. (1971). The use of quinacrine fluorescence in the identification of B and $\mathbf{E}$ group chromosomes involved in structural abnormalities. Fournal of Medical Genetics, 8, 240-243.

Bobrow, M., Pearson, P. L., and Collacott, H. E. A. C. (1971a). Paranucleolar position of the human $\mathrm{Y}$ chromosome in interphase nuclei. Nature, 232, 556-557.

Bobrow, M., Pearson, P. L., Pike, M. C., and El-Alfi, O. S. (1971b). Length variation in the quinacrine-binding segment of human $Y$ chromosomes of different sizes. Cytogenetics, 10, 190-198.

Borgaonkar, D. S. and Hollander, D. H. (1971). Quinacrine fluorescence of the human $\mathrm{Y}$ chromosome. Nature, 230, 52.

Breg, W. R., Miller, O. J., Miller, D. A., and Allderdice, P. W. (1971). Distinctive fluorescence of quinacrine labelled human $G$ group chromosomes. Nature New Biology, 231, 276-277.

Britten, R. J. and Kohne, D. E. (1968). Repeated sequences in DNA. Science, 161, 529-540.

Brookes, P. (1964). In Chemotherapy of Cancer, ed. by P. A. Plattner, pp. 32-43. Elsevier, Amsterdam.

Buckton, K. E., Evans, H. J., O'Riordan, M., and Robinson, J. A. (1971). The use of quinacrine fluorescence in identifying structural rearrangements and points of exchange in human chromosomes. In Fourth International Congress on Human Genetics, Excerpta Medica International Congress Series, No. 233, Amsterdam.

Bühler, E., Frey, R., Müller, H., Voegelin, M., and Stadler, R. (1971). Fluorescence pattern of a dicentric Y. Humangenetik, 12, 170-172.

Caspersson, T., Castleman, K. R., Lomakka, G., Modest, E. J., Møller, A., Nathan, R., Wall, R. J., and Zech, L. (1971a). Automatic karyotyping of quinacrine mustard stained human chromosomes. Experimental Cell Research, 67, 233-235.

Caspersson, T., Chapelle, A. de la, Lindsten, J., Schröder, J., and Zech, L. (1971b). Absence of brightly fluorescent $Y$ material in $\mathrm{XX}$ men. Annales de Génétique, 14, 173-176.

Caspersson, T., Farber, S., Foley, G. E., Kudynowski, J., Modest, E. J., Simonsson, E., Wagh, U., and Zech, L. (1968). Chemical differentiation along metaphase chromosomes. Experimental Cell Research, 49, 219-222.

Caspersson, T., Gahrton, G., Lindsten, J., and Zech, L. (1970a). Identification of the Philadelphia chromosome as a number 22 by quinacrine mustard fluorescent analysis. Experimental Cell Research, 63, 238-239.

Caspersson, T., Hultén, M., Lindsten, J., and Zech, L. (1970b). Distinction between extra G-like chromosomes by quinacrine mustard fluorescence analysis. Experimental Cell Research, 63, 240-242.

Caspersson, T., Hultén, M., Lindsten, J., and Zech, L. (1971c). Exchange de chromatides et duplication du bras court du chromosome 7 chez l'homme. Annales de Génétique, 14, 143-144.

Caspersson, T., Hultén, M., Lindsten, J., and Zech, L. (1971d). Identification of chromosome bivalents in human male meiosis by quinacrine mustard fluorescence analysis. Hereditas, Genetiskt Arkiv, 67, 147-149.

Caspersson, T., Lindsten, J., and Zech, L. (1970c). The nature of structural $\mathbf{X}$ chromosome aberrations in Turner's syndrome as revealed by quinacrine mustard fluorescence analysis. Hereditas, Genetitisk Arkiv, 66, 287-292.

Caspersson, T., Lindsten, J., Zech, L., Buckton, K. E., and Price, W. H. (1972). Four patients with trisomy 8 identified by the fluorescence and Giemsa banding techniques. Fournal of Medical Genetics, 9, 1-7.

Caspersson, T., Lomakka, G., and Zech, L. (1971e). The 24 fluorescence patterns of the human metaphase chromosomes-distinguishing characters and variability. Hereditas, Genetiskt Arkiv, 67, 89-102.

Caspersson, T., Zech, L., Harris, H., Wiener, F., and Klein, G. (1971f). Identification of human chromosomes in a mouse/ human hybrid by fluorescence techniques. Experimental Cell Research, 65, 475-478.

Caspersson, T., Zech, L., Johansson, C., and Modest, E. J. (1970d). Identification of human chromosomes by DNA-binding fluorescent agents. Chromosoma, 30, 215-227.

Caspersson, T., Zech, L., Modest, E. J., Foley, G. E., Wagh, U., and Simonsson, E. (1969a). Chemical differentiation with fluorescent alkylating agents in vicia faba metaphase chromosomes. Experimental Cell Research, 58, 128-140.

Caspersson, T., Zech, L., Modest, E. J., Foley, G. E., Wagh, U., and
Simonsson, E. (1969b). DNA-binding fluorochromes for the study of the organisation of the metaphase nucleus. Experimental Cell Research, 58, 141-152.

Chen, T. R. and Ruddle, F. H. (1971). Karyotype analysis utilizing differentially stained constitutive heterochromatin of human and murine chromosomes. Chromosoma, 34, 51-72.

Chernay, P. R., Hsu, L. Y. F., Streicher, H., and Hirschhorn, K. (1971). Human chromosome identification by differential staining: G group (21-22-y). Cytogenetics, 10, 219-224.

Chicago Conference. Standardization in Human Cytogenetics (1966). Birth Defects: Original Article Series II, 2. The National Foundation-March of Dimes, New York.

Clark, R. J. and Felsenfeld, G. (1971). Structure of chromatin. Nature New Biology, 229, 101-106.

Cohen, M. M., Shaw, M. W., and MacCluer, J. W. (1966). Racial differences in the length of the human $\mathrm{Y}$ chromosome. Cytogenetics, 5, 34-52.

Comings, D. E. (1971). Heterochromatin of the Indian Muntjac. Experimental Cell Research, 67, 441-460.

Cunha, A. B. da, Pavan, C., Morgante, J. S., and Garrido, M. C. (1969). Studies on cytology and differentiation in Sciaridae. II DNA redundancy in salivary gland cells of Hybosciara fragilis (Diptera, Sciaridae). Genetics, 61, Suppl., 335-349.

Dev, V. G., Grewal, M. S., Miller, D. A., Kouri, R. E., Hulton, J. J., and Miller, O. J. (1971). The quinacrine fluorescence karyotype of Mus musculus and demonstration of strain differences in secondary constrictions. Cytogenetics, 10, 436-452.

Drets, M. E. and Shaw, M. W. (1971). Specific banding patterns of human chromosomes. Proceedings of the National Academy of Sciences of the United States of America, 68, 2073-2077.

Dutrillaux, B., Grouchy, J. de, Finaz, C., and Lejeune, J. (1971). Mise en évidence de la structure fine des chromosomes humains par digestion enzymatique (pronase en particulier). Comptes Rendus Hebdomadaires des Séances de l'Académie des Sciences, 273, 587-588.

Dutrillaux, B. and Lejeune, J. (1971). Sur une nouvelle technique d'analyse du caryotype humain. Comptes Rendus Hebdomadaires des Séances de l'Académie des Sciences, 272, 2638-2640.

Evans, H. J., Buckton, K. E., and Sumner, A. T. (1971). Cytological mapping of human chromosomes: results obtained with quinacrine fluorescence and the acetic-saline-Giemsa techniques. Chromosoma, 35, 310-325.

Ferguson-Smith, M. A. (1966). X-Y chromosome interchange in the aetiology of true hermaphroditism and of XX Klinefelter's syndrome. Lancet, 2, 251-255.

Fialkow, P. J., Thomas, E. D., Bryant, J. I., and Neiman, P. E. (1971). Leukaemic transformation of engrafted human marrow cells in vivo. Lancet, 1, 251-255.

François, J., Mutton, D. E., Leuven, M. T. van, and Acosta, J. (1971). Male and female sex determination in hair roots. Clinical Genetics, 2, 73-77.

Franke, U. and Nesbitt, M. (1971). Identification of the mouse chromosomes by quinacrine mustard staining. Cytogenetics, 10, 356-366.

Fourth International Congress on Human Genetics (1971). Excerpta Medica International Congress Series No. 233, Amsterdam.

Gagné, R. and Laberge, C. (1971). Morphologie du corpuscule fluorescent interphasique mis en evidence par la quinacrine chez l'homme. Canadian fournal of Genetics and Cytology, 13, 128-130. Gall, J. G. (1969). The genes for autosomal RNA during oögenesis. Genetics, 61, Suppl., 121-132.

George, K. P. and Polani, P. E. (1970). Y heterochromatin and XX males. Nature, 228, 1215-1216.

Grouchy, J. de, Turleau, C., and Léonard, C. (1971). Etude en fluorescence d'une trisomie $C$ mosaique problement $8: 46, \mathrm{XY} /$ 47, XY, ?8 +. Annales de Génétique, 14, 69-72.

Grzeschik, K. H., Allderdice, P. W., Grzeschik, A., Opitz, J. M., Miller, O. J., and Siniscalco, M. (1972). Cytological mapping of human X-linked genes by use of somatic cell hybrids involving an $\mathrm{X}$-autosome translocation. Proceedings of the National Academy of Sciences of the United States of America, 69, 69-73.

Hamerton, J. L. (1962). Chromosomes in Medicine. (Clinics in Developmental Medicine, No. 5.) Heinemann, London.

Hansen, K. M. (1971). Identification of bovine chromosomes by the quinacrine mustard fluorescence technique. Hereditas, Genetiskt Arkiv, 69, 295. 
Hultén, M. and Pearson, P. L. (1971). Fluorescent evidence for spermatocytes with two Y chromosomes in an XYY male. Annals of Human Genetics, 34, 273-276.

Jones, K. W. and Corneo, G. (1971). Location of satellite and homogeneous DNA sequences on human chromosomes. Nature New Biology, 233, 268-271.

Kasten, F. H. (1966). Cytochemical studies with acridine orange and the influence of dye contaminents in the staining of nucleic acids. International Review of Cytology, 21, 141-202.

Kurnick, K. B. and Radcliffe, I. E. (1962). Reaction between DNA and quinacrine and other antimalarials. Fournal of Laboratory and Clinical Medicine, 60, 669-688.

Lomholt, B. and Mohr, J. (1971). Human karyotyping by heatGiemsa staining and comparison with fluorochrome techniques. Nature New Biology, 234, 109-110.

Malpuech, G., Raynaud, E. J., Belin, J., Godeneche, P., and Grouchy, J. de (1971). Délétion du bras court du 18 par translocation $t(G-; 18 p+)$. Une étude en fluorescence par la moutarde de quinacrine. Annales de Génétique, 14, 213-218.

Manolov, G., Manolova, Y., Levan, A., and Klein, G. (1971). Fluorescent patterns of apparently normal chromosomes in Burkitt lymphomas. Hereditas, Genetiskt Arkiv, 68, 160-163.

McIlree, M. E., Price, W. H., Court Brown, W. M., Tulloch, W. S., Newsam, J. E., and Maclean, N. (1966). Chromosome studies on testicular cells from 50 subfertile men. Lancet, 2 , 69-71.

Miller, D. A., Allderdice, P. W., Miller, O. J., and Breg, W. R. (1971a). Quinacrine fluorescence patterns of human D group chromosomes. Nature, 232, 24-27.

Miller, D. A., Kouri, R. E., Dev, V. G., Grewal, M. S., Hutton, J. J., and Miller, O. J. (1971b). Assignment of four linkage groups to chromosomes in Mus musculus and a cytogenetic method for locating their centromeric ends. Proceedings of the National Academy of Sciences of the United States of America, 68, 2699-2702.

Miller, O. J., Allderdice, P. W., and Miller, D. A. (1971a). Human thymidine kinase gene locus. Assignment to chromosome 17 in hybrid of man and mouse cells. Science, 173, 244-245.

Miller, O. J., Miller, D. A., Allderdice, P. W., Dev, V. G., and Grewal, M. S. (1971b). Quinacrine fluorescent karyotypes of human diploid and heteroploid cell lines. Cytogenetics, 10, 338346.

Miller, O. J., Miller, D. A., Kouri, R. E., Allderdice, P. W., Dev, V. G., Grewal, M. S., and Hutton, J. J. (1971c). Identification of the mouse karyotype by quinacrine fluorescence, and tentative assignment of seven linkage groups. Proceedings of the National Academy of Sciences of the United States of America, 68, 15301533.

Mukherjee, A. B., Blattner, P. Y., and Nitowsky, H. M. (1972). Quinacrine mustard fluorescence of sex chromatin in human amniotic fluid cell cultures. Nature, 235, 226-229.

Ohno, S. (1969). Evolution of sex chromosomes in mammals. Annual Review of Genetics, 3, 495-524.

O'Riordan, M. L., Robinson, J. A., Buckton, K. E., and Evans, H. J. (1971). Distinguishing between the chromosomes involved in Down's syndrome (trisomy 21) and chronic myeloid leukaemia $\mathrm{ph}^{\mathbf{1}}$ by fluorescence. Nature, 230, 167-168.

Pardue, M. L. and Gall, J. G. (1970). Chromosome localization of mouse satellite DNA. Science, 168, 1356-1358.

Paris (Orly) Conference 1971: Standardization in Human Cytogenetics (1972). Birth Defects: Original Article Series. The National Foundation-March of Dimes, New York. (In press.)

Patil, S. R., Merrick, S., and Lubs, H. A. (1971). Identification of each human chromosome with a modified Giemsa stain. Science, 173, 821-822.
Pearson, P. L. (1970). A fluorescent technique for identifying human chromatin in a variety of tissues. Bulletin of the European Society of Human Genetics, 4, 35-38.

Pearson, P. L. and Bobrow, M. (1970a). Fluorescent staining of the $\mathrm{Y}$ chromosome in meiotic stages of the human male. Fournal of Reproduction and Fertility, 22, 177-179.

Pearson, P. L. and Bobrow, M. (1970b). Definitive evidence for the short arm of the $\mathrm{Y}$ chromosome associating with the $\mathrm{X}$ chromosome during meiosis in the human male. Nature, 226, 959-961.

Pearson, P. L., Bobrow, M., and Madan, K. (1972). The chromosome banding patterns of the hominoid apes. (In preparation.)

Pearson, P. L., Bobrow, M., and Vosa, C. G. (1970). Technique for identifying $\mathrm{Y}$ chromosomes in human interphase nuclei. Nature, 226, 78-80.

Pearson, P. L., Bobrow, M., Vosa, C. G., and Barlow, P. W. (1971). Quinacrine fluorescence in mammalian chromosomes. Nature, 231, 326-329.

Polani, P. E. and Mutton, D. E. (1971). Y-fluorescence of interphase nuclei, especially circulating lymphocytes. British Medical Fournal, 1, 138-142.

Ridler, M. A. C. (1971). Banding patterns of metaphase chromosomes in Down's syndrome. Lancet, 2, 354-356.

Ritossa, F. M., Atwood, K. C., Lindsley, D. L., and Spiegelman, S. (1966). On the chromosomal distribution of DNA complementary to ribosomal and soluble RNA. National Cancer Institute Monographs, 23, 449-471.

Robinson, J. (1971). Y chromosome fluorescence in buccal mucosa cells. Annals of Human Genetics, 35, 61-65.

Robinson, J. A. and Buckton, K. E. (1971). Quinacrine fluorescence of variant and abnormal human $\mathrm{Y}$ chromosomes. Chromosoma, 35, 342-352.

Rowley, J. D. and Bodmer, W. F. (1971). Relationship of centromeric heterochromatin to fluorescent banding patterns of metaphase chromosomes in the mouse. Nature, 231, 503-506.

Saunders, G. F., Hsu, T. C., Getz, M. J., Simes, E. L., and Arrighi, F. E. (1972). Locations of a human satellite DNA in human chromosomes. Nature. (In press.)

Schnedl, W. (1971a). Analysis of the length variation in the human $Y$ chromosome by aid of quinacrine fluorochrome method. Humangenetik, 12, 188-194.

Schnedl, W. (1971b). Analysis of the human karyotype using a reassociation technique. Chromosoma, 34, 448-454.

Schnedl, W. (1971c). The karyotype of the mouse. Chromosoma, 35, 111-116.

Schwinger, E., Rakebrand, E., Müller, H. J., Bühler, E. M., and Tetterborn, U. (1971). Y-body in hair roots. Humangenetik, 12, 79-80.

Seabright, M. (1971). Rapid banding technique for human chromosomes. Lancet, 2, 971-972.

Steel, C. M. (1971). Non-identity of apparently similar chromosome aberrations in human lymphoblastoid cell lines. Nature, 233, 555-556.

Stevenson, A. C., Bedford, J., and Barberton, G. M. (1971). A patient with 45,X/46,XXq - /46,XXq - dic karyotype. fournal of Medical Genetics, 8, 513-516.

Sumner, A. T., Evans, H. J., and Buckland, R. A. (1971a). New technique for distinguishing between human chromosomes. Nature New Biology, 232, 31-32.

Sumner, A. T., Robinson, J. A., and Evans, H. J. (1971b). Distinguishing between $\mathrm{XY}$ and $\mathrm{YY}$-bearing human spermatozoa by fluorescence and DNA content. Nature New Biology, 229, 231233.

Wang, H. C. and Fedoroff, S. (1972). Banding in human chromosomes treated with trypsin. Nature New Biology, 235, 52-54.

Zech, L. (1969). Investigation of metaphase chromosomes with DNA binding fluorochromes. Experimental Cell Research, 58, 463. 